This item was submitted to Loughborough's Research Repository by the author.

Items in Figshare are protected by copyright, with all rights reserved, unless otherwise indicated.

\title{
Are fiscal deficits inflationary in African countries? A new evidence from an asymmetric cointegration analysis
}

PLEASE CITE THE PUBLISHED VERSION

https://doi.org/10.1016/j.najef.2019.100999

PUBLISHER

(C) Elsevier

VERSION

AM (Accepted Manuscript)

\section{PUBLISHER STATEMENT}

This paper was accepted for publication in the journal The North American Journal of Economics and Finance and the definitive published version is available at https://doi.org/10.1016/j.najef.2019.100999.

LICENCE

CC BY-NC-ND 4.0

\section{REPOSITORY RECORD}

Ahmad, Ahmad Hassan, and Olalekan B. Aworinde. 2019. "Are Fiscal Deficits Inflationary in African Countries? A New Evidence from an Asymmetric Cointegration Analysis". Loughborough University. https://hdl.handle.net/2134/37925. 


\title{
Are Fiscal Deficits Inflationary in African Countries? A New Evidence from an Asymmetric Cointegration Analysis*
}

\author{
Ahmad Hassan Ahmad ${ }^{\dagger} \quad$ Olalekan B. Aworinde ${ }^{\ddagger}$
}

\begin{abstract}
This paper investigates relationship between fiscal deficits and inflation in a sample of twelve African countries using quarterly series, covering the period from 1980:1 to 2018:4. It uses the Enders and Siklos (2001) technique that accommodates asymmetric adjustments between the series, which suits African countries with imperfect and underdeveloped financial market systems where adjustments may be sporadic and contingent. The results indicate that there is a long-run relationship between fiscal deficits and inflation in all the countries and fiscal deficit is inflationary, which indicates importance of fiscal consolidation. It is also found that adjustments between the series are asymmetric in these countries.
\end{abstract}

Key Words: Fiscal deficits, Inflation, Cointegration, Asymmetric adjustments, Africa countries.

JEL Classification: E31 H60, H62, C22,

${ }^{*}$ We are very grateful to the editor and the anonymous reviewer for the useful and constructive comments.

${ }^{\dagger}$ Corresponding author. School of Business \& Economics, Loughborough University, Leicestershire, LE11 3TU, United Kingdom. A.H.Ahmad@lboro.ac.uk

${ }^{\ddagger}$ Department of Economics, University of Bath, Bath, BA2 7YA, United kingdom and Department of Economics, School of Management \& Social Sciences Pan-Atlantic University, Lagos, Nigeria. 


\section{Introduction}

Large and sustained government budget deficits and inflation are major concerns in both developed and developing countries. Part of the concern stems from the view that large fiscal deficits result in high real interest rates, thus crowding out private investment, hindering capital formation and adversely affecting rate of economic growth in the economy. This will put an upward pressure on prices as the same amount of money chasing less good (Miller, 1983). Similarly, monetary authorities would be forced to implement monetary accommodation policy or even to monetize the public debts in the context of developing countries that are characterized with less efficient revenue collection systems, political instability and limited access to external borrowings. These may lower the cost of seinorage and make inflation tax more attractive. This is what is argued by Sargent and Wallace (1981) where they portend that seigniorage assumes the central role for deficit finance in that the central bank will be obliged to monetize the deficit. Such monetization results in an increase in the money supply and in the rate of inflation. In this respect, a number of work on developing countries have reported significant relationship between inflation and fiscal deficits, particularly during the high inflation periods (see for example, De Haan and Zelhorst (1990) and Domac and Yucel (2005). Barro (1978, 1979), on the other hand, suggests that fiscal deficits are as a result of inflation. The government deficit leads to positive change in the nominal value of outstanding government debts. If the anticipated inflation rate increases, then the nominal value of debts must also increase. That is, the government will run a deficit in order to keep the same anticipated real amount of debts. Direct relationship between fiscal deficit and inflation is identified by Patinkin (1965), using the aggregate demand approach. He argues that a rise in the real value of the stock of bonds increases perceived private wealth, and therefore, leads to increase in spending that results in raising the inflation rate. Elmendorf and Mankiw (1999) elaborate on Patinkin's (1965) argument by providing supporting empirical evidence. Empirical studies on developed countries reported inconclusive results on the nature of the relationship between the series (for example, see Hamburger and Zwick, 1981; Dwyer, 1982; Darrat, 1985; Ahking and Miller, 1985; King and Plosser, 1985; Giannaros and Kolluri, 1986; Protopapadakis and Siegel, 1987).

Previous studies have used models that assume symmetric adjustment between the series while responding to a shock. However, adjustment may be asymmetric, particularly with regards to inflation. The "plucking model" of Friedman $(1964,1993)$ provides the economic underpinning for asymmetric adjustment in inflation. Friedman $(1964,1993)$ argues that output cannot outpace a ceiling level, but it is some- 
times "plucked downward", which leads to asymmetry between upturns and downturns. Secondly, the countries in the sample, except South Africa, do not have fully developed financial markets, which constitute a great barrier to their borrowing abilities. Fiscal decisions could, therefore, be haphazard that can lead to sporadic and contingent adjustments.

The main objective of this paper is to contribute to this area by examining the relationship between fiscal deficits and inflation in twelve African countries within an asymmetric framework, which also allows for different speeds of adjustment to the long-run relationship depending on whether fiscal deficits and inflation are above or below equilibrium. These countries are commodity dependent, which are exposed to vulnerability of terms of trade shocks. These shocks have adverse effects on both the countries' current account and public revenues. It is as consequent of this that the countries in the sample have to introduce one form of structural reforms or the other in order to address the problem in the 1980s and 1990s. The countries have also experienced high inflation until recently. A notable exception in the sample is Botswana. Fiscal deficits and their financing are the major source of concern for policy makers in these countries as they could impact on the economy in different ways including high inflation. The structural adjustment programmes backed by the International Monetary Fund (IMF) and the World Bank to African countries in the 1980 s and the 1990s focused on reduction of the size of the public sector and on promoting private sector involvement that would help in promoting productivity in the economies. Economic diversifications were also part of the package, which were aimed at reducing high dependence on an unstable oil price or exports of other few raw materials that the countries depend upon.

The rest of the paper is structured as follows. Section 2 outlines the methodology of Enders and Siklos (2001) that combines cointegration and threshold adjustment used in the paper. Section 3 analyses the data and discusses the estimated results while Section 4 concludes.

\section{Methodology}

The threshold autorgressive (TAR) and momentum-threshold autorgressive (M-TAR) tests of Enders and Siklos (2001) are applied to investigate the relationship between inflation and fiscal deficits in Africa. As discussed above, relationship between inflation and fiscal deficits is likely to be non-linear. For example, Arize and Malindretos (2012) have reported existence of nonlinearity of inflation in African countries. Enders and Siklos (2001) explain that linear cointegration models which only allow symmetric adjustments could be biased and mis-specified when the relationship is 
non-linear with potential asymmetric adjustment behaviours. Sollis, Leybourne and Newbold (2002), Kapetanios, et al (2003), Sollis (2009) and Arize and Malindretos (2012), among others have highlighted importance of using appropriate models to estimate series that generate asymmetries and nonlinearity. Enders and Siklos (2001) technique detects cointegration even when nonlinearity exists between the series, and also allows symmetric adjustments between the series. Therefore, for the advantages of the Enders and Siklos (2001) asymmetric cointegration has over symmetric cointegration, particularly in separating the error correction effects into positive and negative, the paper adapts it. Symmetric cointegration tests, such as Engel-Granger and the Johansen techniques may fail to detect existence of cointegration relationship when series exhibit these characteristic: 1 ?

Relationship between inflation and fiscal deficits can be expressed as:

$$
I N F R_{t}=\alpha_{0}+\alpha_{1} F D_{t}+\varepsilon_{t}
$$

where $I N F R_{t}$ is the inflation rate, $F D_{t}$ represents the fiscal deficits as a percentage of the GDP and $\varepsilon_{t}$ is a stochastic error term. After, performing a long-run linear regression test on equation (1), unit root tests are performed on the residual series, $\varepsilon_{t}$. The tests take the following form:

$$
\Delta \varepsilon_{t}=\rho \varepsilon_{t-1}+v_{t}
$$

where $\left\{\varepsilon_{t}\right\}$ contains the regression residuals from equation (1) and assumed to be purely white noise with a zero mean and a constant variance and $v_{t}$ is an independent and identically distributed disturbance with zero mean. If the null hypothesis of $\rho=0$ can be rejected, then $\left\{\varepsilon_{t}\right\}$ is stationary. The model assumes a symmetric adjustment process. According to equation (2), the change in $\varepsilon_{t}$ is $\rho \varepsilon_{t-1}$ regardless of whether $\varepsilon_{t-1}$ is positive or negative. But, if the inflation rate and fiscal deficits adjustments are asymmetric, then equation (2) is mis-specified. Enders and Siklos (2001) propose two test of asymmetries; a TAR and an M-TAR models. The TAR model tests for asymmetric adjustment in inflation when $\varepsilon_{t} \geq 0$, or $\varepsilon_{t}<0$ and is given as:

$$
\Delta \varepsilon_{t}=I_{t} \rho_{1} \varepsilon_{t-1}+\left(1-I_{t}\right) \rho_{2} \varepsilon_{t-1}+v_{t}
$$

where $I_{t}$ is the Heaviside indicator such that

$$
I_{t}=\left\{\begin{array}{lll}
1 & \text { if } & \varepsilon_{t-1} \geq \tau \\
0 & \text { if } & \varepsilon_{t-1}<\tau
\end{array}\right\}
$$

\footnotetext{
${ }^{1}$ However, for robustness, the symmetric cointegration of Johansen test is also used in the paper
} 
where $\tau$ is the value of the threshold and it is endogenously determined using the Chan (1993) method. The Chan method arranges the values, $\left(\varepsilon_{t}\right)$ and $\left(\Delta \varepsilon_{t}\right)$ for the TAR and the M-TAR models respectively in ascending order and excludes the smallest and the largest $15 \%$ to make $\tau$ a consistent estimate that yields the smallest residual sum of squares over the remaining $70 \%$.

The second hypothesis examines whether fiscal deficits deviations are corrected instantaneously when inflation rate increase relative to $\varepsilon_{t} \geq 0$, than when they decrease relative to the $\varepsilon_{t}<0$. This is tested using the M-TAR model of Enders and Siklos (2001), which takes the following form:

$$
\Delta \varepsilon_{t}=M_{t} \rho_{1} \varepsilon_{t-1}+\left(1-M_{t}\right) \rho_{2} \varepsilon_{t-1}+v_{t}
$$

where $M_{t}$ is the Heaviside indicator function:

$$
M_{t}=\left\{\begin{array}{lll}
1 & \text { if } \quad \Delta \varepsilon_{t-1} \geq \tau \\
0 & \text { if } \quad \Delta \varepsilon_{t-1}<\tau
\end{array}\right\}
$$

As stated by Petrucelli and Woolford (1984) the necessary condition for the stationarity of $\varepsilon_{t}$ are that $\rho_{1}<0, \rho_{2}<0$ and $\left(1+\rho_{1}\right)\left(1+\rho_{2}\right)<1$. If $\varepsilon_{t-1}$ is above the long-run equilibrium value, then adjustment is at the rate $\rho_{1}$ and if $\varepsilon_{t-1}$ is below the long-run equilibrium value then adjustment is at the rate $\rho_{2}$. Adjustment is symmetric if $\rho_{1}=\rho_{2}$. The M-TAR model is useful when the adjustment exhibits more momentum in one direction than the other. That is the speed of adjustment depends on whether $\Delta \varepsilon_{t-1}$ is increasing or decreasing. If $\left|\rho_{1}\right|<\left|\rho_{2}\right|$, then increases in $\Delta \varepsilon_{t-1}$ may tend to persist.

If the errors in equations (3) and (5) are serially correlated, the models are replaced with:

$$
\begin{gathered}
\Delta \varepsilon_{t}=I_{t} \rho_{1} \varepsilon_{t-1}+\left(1-I_{t}\right) \rho_{2} \varepsilon_{t-1}+\sum_{i=1}^{p} \beta_{i} \Delta \varepsilon_{t-i}+v_{t} \\
\Delta \varepsilon_{t}=M_{t} \rho_{1} \varepsilon_{t-1}+\left(1-M_{t}\right) \rho_{2} \varepsilon_{t-1}+\sum_{i=1}^{p} \gamma_{i} \Delta \varepsilon_{t-i}+v_{t}
\end{gathered}
$$

Equations (7) and (8) are for TAR and M-TAR model that address the serial correlation problem.

If cointegration is established between inflation rate and fiscal deficit as well as asymmetric adjustment, then the asymmetric version of the error correction model 
(ECM) is given as;

$$
\begin{aligned}
& \Delta I N F R_{t}=\rho_{11} I_{t} \varepsilon_{t-1}+\rho_{12}\left(1-I_{t}\right) \varepsilon_{t-1}+\sum_{i=1}^{p} \delta_{k} \Delta F D_{t-i}+\sum_{i=1}^{p} \eta_{k} \Delta I N F R_{t-i}+v_{1 t} \\
& \Delta F D_{t}=\rho_{11} I_{t} \varepsilon_{t-1}+\rho_{12}\left(1-I_{t}\right) \varepsilon_{t-1}+\sum_{i=1}^{p} \varphi_{k} \Delta F D_{t-i}+\sum_{i=1}^{p} \psi_{k} \Delta I N F R_{t-i}+v_{2 t} \text { (10) } \\
& \Delta I N F R_{t}=\rho_{11} M_{t} \varepsilon_{t-1}+\rho_{12}\left(1-M_{t}\right) \varepsilon_{t-1}+\sum_{i=1}^{p} \delta_{k} \Delta F D_{t-i}+\sum_{i=1}^{p} \eta_{k} \Delta I N F R_{t-i}+v_{1 t} \\
& \Delta F D_{t}=\rho_{11} M_{t} \varepsilon_{t-1}+\rho_{12}\left(1-M_{t}\right) \varepsilon_{t-1}+\sum_{i=1}^{p} \varphi_{k} \Delta F D_{t-i}+\sum_{i=1}^{p} \psi_{k} \Delta I N F R_{t-i}+v_{2 t}
\end{aligned}
$$

Equations (9) and (10) is for the TAR model while (11) and (12) represent the M-TAR model. They describe the dynamic relationship between fiscal deficits and inflation rate as well as examine the speed of adjustments of the series. The parameters $\rho_{i t}$ represent the error correction coefficients. If there is a deviation from long-run equilibrium, and the deviation happens to be positive, depending on the Heaviside indicator, then the speed of adjustment is given by $\rho_{11}$ in equations (9) and (10) for the TAR model. Similarly for negative deviations defined by the Heaviside indicator, the speed of adjustment is given by $\rho_{12}$.

\section{Data and the Estimated Results}

The data-set is sourced from the IMF's International Financial Statistics database, covering the period from 1980:1 to 2018:4 that consists of quarterly series of fiscal deficits and inflation rates for the twelve countries in the sample. The countries are Botswana, Cameroon, Egypt, Ethiopia, Ghana, Kenya, Morocco, Nigeria, South Africa, Tanzania, Tunisia and Uganda. The fiscal deficit (FD) is constructed as difference between total revenue and total expenditure and expressed as a percentage of GDP. This follows the literature, particularly, Holme (2011) where the positive figures represent surplus and negative values signify deficits. Figure 1 depicts the 
FD variable for the countries covered. It shows that it is negative and therefore signifies deficits in ten out of twelve countries in the sample ${ }^{2}$. The countries where the variable is positive and indicates surplus are Botswana and Cameroon. The former has been acknowledged as the best performing economy on the continent and have implemented sound macroeconomic policies that has made the country escapes from the natural resources "curse" despite it is heavily dependent on diamond 3 . The latter is the only country in the sample that participates in a monetary union, Central Africa CFA zone. This might have positive impact on the country's fiscal discipline. Inflation rate (INFR) is quarterly percentage changes in consumer prices, IFS line AE 64. The series were subjected to unit root tests using the Augmented Dickey Fuller and the Philip Perron tests and the results are presented in Table 1. The reported results indicate that the null of unit root was failed to be rejected on the series levels but rejected on first difference for all the twelve countries. Subsequently asymmetric cointegration tests of Enders and Siklos (2001) were conducted on the twelve countries where both the fiscal deficits and inflation rates are $\mathrm{I}(1)$ variables. ${ }^{4}$

Linear cointegration tests were conducted on the series using the Johansen technique and the results are reported in Tables 2 and 3. The tests are performed on the model specified in equation (1). The results show that there a long-run relationship between the two series in all the twelve countries and the null of no cointegration was rejected. The estimated cointegrating vectors are positive apart from Botswana and Cameroon. This is interesting as these are the countries, where the variable FD was mostly positive for the sample period. This indicates that the results are consistent in all the countries when it is realized for the two countries, the variable represents fiscal surplus where as it is fiscal deficit in the rest of the countries.

Table 4 reports results for the estimated TAR model. The $\rho_{1}$ and $\rho_{2}$ estimates are presented, with the $\phi_{u}$ statistics for null hypothesis of no asymmetric cointegration, $H_{0}:\left(\rho_{1}=\rho_{2}=0\right)$ and the standard F-statistic test for the null hypothesis of symmetric cointegration, $H_{0}:\left(\rho_{1}=\rho_{2}\right)$. It is evident from Table 4 , the estimates of $\rho_{1}=\rho_{2}$ are negative which are anticipated for stationarity of the error term, except $\rho_{2}$ for Ghana and Uganda. The $\phi_{u}$ test of no cointegration is rejected for nine countries using the TAR model. This is consistent with the results obtained from the Engle-Granger test for South Africa, Tanzania and Uganda. Results for South

\footnotetext{
${ }^{2}$ The summary statistics of the series indicates that it is only in these two countries that the variable has a positive mean values.

${ }^{3}$ See Acemoglu, et al (2003) and Hillbom (2012) for further details.

${ }^{4}$ Considering the low power of these tests, particularly, the ADF, we have also conducted the LM test that is more roburst and accommodates up to two structural breaks. However, the results also suggest failure of rejection of null hypothesis of non stationarity in favour of the alternative. The results are not reported in the paper, but available on request.
} 
Africa, Tanzania and Uganda indicate that the null hypothesis of no cointegration could not be rejected. The null hypothesis of symmetric adjustment could not be rejected for Twelve countries while it is rejected for only Tanzania. This might not be unconnected to high inflation periods experienced by the countries, particularly during the 1980s and the 1990s. Results for Nigeria indicate that $\left|\rho_{1}\right|<\left|\rho_{2}\right|$, which implies that inflation adjustment is quicker upward than downward. The results for Botswana and Cameroon show the opposite. That is inflation adjusts quicker downward than upward. This might be due to the role of exchange rate regimes. Nigeria has been on flexible exchange rate regime for almost the entire sample period while Botswana and Cameroon have been on peg regime and monetary union, respectively.

Table 5 reports the M-TAR models, where the M-TAR model with $\tau=0$ shows that the estimates of the autoregressive decay, $\rho_{1}$ and $\rho_{2}$ have negative signs. Column 4 shows the test for asymmetric cointegration. The null hypothesis of $H_{0}:\left(\rho_{1}=\rho_{2}=0\right)$ was rejected in seven countries at various levels of significance, it is only in Egypt, South Africa, Tanzania, Tunisia and Uganda where the null could not be rejected. The null of symmetric cointegration was rejected only for Ethiopia and Ghana. Also, $\left|\rho_{1}\right|<\left|\rho_{2}\right|$, in Botswana, Cameroon, Ethiopia and Kenya this implies that when inflation and fiscal deficits are increasing, the disequilibrium between the inflation rate and the fiscal deficits are corrected at a slower rate relative to when they are both decreasing. Using a consistent M-TAR model, the point estimates of $\rho_{1}$ and $\rho_{2}$ have negative signs. Also, the case for asymmetric adjustment is substantially strengthened when a consistent estimate of the threshold is used with all the twelve countries showing asymmetric adjustment. Symmetric adjustment $H_{0}:\left(\rho_{1}=\rho_{2}\right)$ is rejected at all conventional levels of significance in ten countries. This is consistent with prediction of Friedman's $(1964,1993)$ "plucking model" discussed in the introduction. The study also revealed that $\left|\rho_{1}\right|>\left|\rho_{2}\right|$, in Ghana, Kenya, South Africa, Tanzania, Tunisia and Uganda this implies that inflation and fiscal deficits have higher momentum upward relative to their long-run levels than downward.

It is clear from the above that the TAR results reported, it is results for Botswana, Egypt, Ethiopia, Ghana, Morocco, Nigeria and Tunisia that all the conditions are fulfilled, that is, there is the presence of non-linear cointegration, the null hypothesis $H_{0}:\left(\rho_{1}=\rho_{2}=0\right)$ was rejected and the null hypothesis $H_{0}:\left(\rho_{1}=\rho_{2}\right)$; of symmetric adjustment were also rejected. However, for the M-TAR model all the conditions were fulfilled for Botswana, Egypt, Ethiopia, Ghana, Morocco, South Africa, Tanzania, Tunisia and Uganda. Using the Alkaike information criterion, it is found that the M-TAR model is preferred for Egypt, Ethiopia, Kenya, South Africa, Tanzania and Tunisia, while the TAR model is preferred for Botswana, Ghana, Morocco, 
Nigeria and Uganda. The implication of this is that adjustment is asymmetric for fiscal deficits and inflation in these Twelve countries and that the TAR and M-TAR specification have superior power properties than the Engle-Granger or any other linear cointegration tests. Since cointegration exists and also that each cointegrating relationship is described by asymmetric adjustment for Botswana, Egypt, Ethiopia, Ghana, Kenya, Morocco, Nigeria, South Africa, Tanzania, Tunisia and Uganda then asymmetric error-correction models for these countries were estimated. These are reported in Table 6 .

The results in Table 6 reports the point estimates of $\rho_{11}$ and $\rho_{12}$ determine the speed of adjustment for positive and negative deviations for long-run relationship between fiscal deficits and inflation rate. Results for Botswana show that estimates of $\rho_{11}$ and $\rho_{12}$ adjust back to equilibrium, however, the t-statistic for the error correction indicates that the inflation rate adjusts to negative discrepancy but does not adjusts to positive discrepancy. The result also shows that the inflation rate adjusts faster in the negative discrepancy than the positive. The adjustment mechanism shows that when inflation is rising, deviations from equilibrium are corrected at a slower rate, about 12 per cent of the deviations are corrected quarterly while when it is falling, about 21 per cent of the deviations are corrected quarterly. The error correction coefficient shows that fiscal deficits adjust by 15 per cent of a positive gap, and this shows that fiscal deficits respond to positive deviations but not negative deviations.

Estimates of $\rho_{11}$ and $\rho_{12}$ for Egypt adjust back to equilibrium, and the t-statistic for the error correction term indicates that the inflation rate adjusts to both positive and negative discrepancy. Adjustments in inflation is similar to those of Botswana negative adjustment is faster than positive, and this is consistent with the results obtained from the M-TAR model. The adjustment mechanism shows that when inflation is rising, 19 per cent of the deviations are corrected quarterly, but about 44 per cent of the deviations are corrected quarterly downwardly. Also, fiscal deficits adjust to a positive discrepancy, this implies that when fiscal deficits are increasing about 14 per cent of the deviations are adjusted back to equilibrium. Similar results were also reported for Ethiopia, the results indicate that a contemporaneous response of inflation changes is greater for negative discrepancy than positive discrepancy with 32 per cent of the deviations corrected when inflation is increasing, and 57per cent of the deviation adjusted back to equilibrium when inflation is decreasing. However, fiscal deficits changes are greater for positive discrepancy than negative discrepancy, with approximately 45 per cent of the deviations corrected when fiscal deficits are increasing and 21 per cent of the deviations adjusted back to equilibrium when fiscal deficits is reducing.

However, in Ghana, the t-statistic for the error correction terms indicates that 
inflation and fiscal deficits adjusts to positive and negative discrepancies. Inflation adjusts faster when the discrepancy is widening, with 53 per cent of the deviation adjusted back to equilibrium, compared to when inflation is narrowing with approximately 32 per cent adjusting back to equilibrium. However, when the fiscal deficit is widening, 62 per cent of the deviation adjusts back to equilibrium, and 23 per cent of the deviations adjust back to equilibrium when fiscal deficits are narrowing. Results for Kenya exhibit similar pattern to that of Ghana where the error correction terms show that both inflation and fiscal deficits adjust quicker to positive discrepancies. Inflation adjusts about 57 per cent of the deviations adjust back to equilibrium upwardly, while when the fiscal deficit records about 26 per cent of the deviations are adjust back to equilibrium in the same direction. In the case of Morocco, we found that the speed of adjustment in the inflation rate is much more rapid under a widening discrepancy than when the deviation is narrowing, and this is consistent with the TAR model on the speed of adjustment reported in Table 6. This implies that inflation adjust much more rapidly to a positive discrepancy than to a negative discrepancy. However, the t-statistic for the error correction term for fiscal deficits does not adjust to positive and negative discrepancies.

In Nigeria, the t-statistic for the error correction terms indicates that inflation and fiscal deficits adjusts to positive and negative discrepancies. Inflation adjusts faster when the discrepancy is widening, with 49 per cent of the deviation adjusted back to equilibrium, compared to when inflation is narrowing with approximately 29 per cent adjusting back to equilibrium. However, when the fiscal deficit is widening, 50 per cent of the deviation adjusts back to equilibrium, and 15 per cent of the deviations adjust back to equilibrium when fiscal deficits are narrowing. Similar results are found in the case of South Africa, the t-statistic for the error correction terms indicates that inflation and fiscal deficits adjusts to positive and negative discrepancies. Inflation adjusts faster when the discrepancy is increasing, with 23 per cent of the deviation adjusted back to equilibrium, compared to when inflation is narrowing with approximately 20 per cent adjusting back to equilibrium. However, when the fiscal deficit is widening, 17 per cent of the deviation adjusts back to equilibrium, and 31 per cent of the deviations adjust back to equilibrium when fiscal deficits are narrowing.

In Tanzania, the result also shows that the inflation rate adjusts faster in the positive discrepancy than negative discrepancy, and this is consistent with the MTAR model on the speed of adjustment. The adjustment mechanism shows that when inflation is rising, deviations from equilibrium are corrected at a faster rate, with 59 per cent of the deviations corrected quarterly while when inflation is falling, 21 per cent of the deviations are corrected quarterly. The error correction term for 
the fiscal deficits adjust by 44 per cent of a positive gap, and this shows that fiscal deficits respond to positive deviations but not negative deviations. Result in Tunisia shows that the t-statistic for the error correction terms indicates that inflation and fiscal deficits adjusts to positive and negative discrepancies. Inflation adjusts faster when the discrepancy is widening, with 41 per cent of the deviation adjusted back to equilibrium, compared to when inflation is narrowing with about 17 per cent adjusting back to equilibrium. However, when the fiscal deficit is widening, 49 per cent of the deviation adjusts back to equilibrium, and 23 per cent of the deviations adjust back to equilibrium when fiscal deficits are narrowing.

Results for Uganda show that estimates of $\rho_{11}$ and $\rho_{12}$ adjust back to equilibrium, however, the t-statistic for the error correction indicates that the inflation rate adjusts to negative discrepancy but does not adjusts to positive discrepancy. The result also shows that the inflation rate adjusts faster in the positive discrepancy than the negative. The adjustment mechanism shows that when inflation is rising, deviations from equilibrium are corrected at about 41 per cent of the deviations are corrected quarterly while when it is falling and that the inflation rate do not respond to negative deviations. The error correction coefficient shows that fiscal deficits adjust by 49 and 17 per cent of positive and negative gap, this shows that fiscal deficits respond to both positive and negative deviations.

Considering estimates of the cointegrating vectors reported in Tables 2 and 3 along with $\rho_{11}$ estimates in Tables 4 and 5, they suggest that fiscal deficit is inflationary in all the Twelve countries. This is because a negative $\rho_{11}$ with a cointegrating vector $(1,-)$ indicate that a fall in FD will lead to a higher inflation rate while a cointegrating vector $(1,+)$ with a negative $\rho_{11}$ would suggest a fall in FD leads to a lower inflation rate. Looking at the results reveals that the estimates of $\rho_{11}$ for all the countries are negative and the cointegrating vectors are $(1 ;+)$, except for Botswana and Cameroon where they are $(1,-)$ : Bearing in mind that FD variable signifies fiscal deficit for these countries as discussed above, it means that the results are consistent, and that fiscal deficit is inflationary for all the Twelve countries.

From the foregoing, it was observed that there is asymmetric cointegration in Twelve countries out of twelve countries investigated. In countries where cointegration were found namely, Botswana, Egypt, Ethiopia, Ghana, Kenya, Morocco, Nigeria, South Africa, Tanzania, Tunisia and Uganda we observe that this might be attributed to the sound macroeconomic policies embarked upon by these economies.

For example, in Ghana, where the model performs better, the government of this country took decisive macroeconomic actions, among which includes fiscal, monetary and institutional reforms to achieve anticipated level of growth. The fiscal reforms involve a reduction of government expenditure, removal of subsidies, as well 
as improved system of tax collection. The monetary reforms include contractionary monetary policy, introduction of income policies as well as the reduction of import restrictions to allow the imports of much needed inputs and spare parts necessary for the production of goods and services. The institutional reforms engaged in include the retrenchment and redeployment of labour, as well as privatization and commercialization of state-owned enterprise. Similarly, countries where asymmetric cointegrations were found are those countries where implementation as well as adequate commitment were given to the structural adjustment programmes, which helps in trimming down the over bloated government expenditure, payment of foreign debts, exchange rate stability as well increase in the flow of foreign direct investment.

Another thing worth noting from the above results is the possibility of important role played by exchange rate regimes operated by these countries. Botswana, Egypt and Ethiopia have been on peg exchange rate regimes for most of the period covered. The results reported show that inflation adjustments in these countries are quicker downward than upward whereas results for countries that operate flexible exchange rates for most of the sample period, which include Ghana, Kenya and Nigeria, inflation adjustments are faster when adjusting upward than downward. Based on the monetary models of exchange rates 5 , when monetary authorities monetize the public debts under the fixed exchange rate regime, rise in domestic money supply leads to depletion of foreign reserves in order to bring down price level to its long-run level. This facilitates quicker downward adjustment of inflation in countries operating peg regimes. Monetizing public debts under floating regime, on the other hand, consequent to monetary expansion, price level rises and accompanied with exchange rate depreciation to maintain its long-run level. Therefore, countries on flexible exchange rate regimes find upward adjustment of price level quicker.

\section{Conclusion}

This paper investigates relationships between fiscal deficit and inflation in twelve African countries. The paper uses the threshold autoregressive (TAR) and the momentum threshold autoregressive (M-TAR) developed by Enders and Siklos (2001), which accommodates non-linearity and asymmetric adjustment between the series. The results show that the behaviour these series exhibit asymmetries in most of the countries covered. This is not surprising as fiscal adjustments in these countries are generally ad hoc and financial markets of these countries are not fully developed.

Symmetric cointegration tests of Engle and Granger and those of Johansen found

\footnotetext{
${ }^{5}$ For full details, see Frankel $(1976,1979)$ and Taylor (1995).
} 
presence of long-run relationship between fiscal deficits and inflation in nine out of twelve countries covered. However, when the TAR model was used, long-run relationships between the series are found for Botswana, Egypt, Ethiopia, Ghana, Morocco, Nigeria and Tunisia. Results from the M-TAR model revealed that asymmetric cointegrating relationship in eight countries. These are Botswana, Egypt, Ethiopia, Ghana, Morocco, South Africa, Tanzania, Tunisia and Uganda. Using the information criterion, it is found that the M-TAR model is preferred for Egypt, Ethiopia, Kenya, South Africa, Tanzania and Tunisia, while the TAR model is preferred for Botswana, Ghana, Morocco, Nigeria and Uganda. It was also observed that the asymmetric error correction term shows that inflation adjust to both negative and positive discrepancy in most countries, whereas fiscal deficits adjust to only positive discrepancy, except for South Africa where fiscal deficits adjust to negative discrepancy. In addition, it was also found that inflation is inflationary in these Twelve countries. This is consistent with the postulates in the literature that downward adjustment of public finance is difficult, particularly in developing countries due to political pressure and as results the countries resort to inflation tax.

In addition, the economic structures of these economies might be a factor for the asymmetric adjustment found in the results. For example, countries like Botswana and Egypt where peg regimes are operated, upward adjustment is slower than countries with more flexible exchange rates, such as Ghana, Kenya and Morocco. 


\section{References}

Acemoglu, D., Johnson, S. and Robinson, J. A. (2003) 'Botswana: An African Success', In Search of Prosperity: Analytical Narratives on Economic Growth, ed. Rodrik, D., 80-119. Princeton: Princeton University Press.

Arize, Augustine C. and John Malindretos (2012) Nonstationarity and nonlinearity in inflation rate: Some further evidence, International Review of Economics \& Finance, Volume 24, Pages 224-234

Ahking, F.W. \& Miller, S. M. (1985), 'The relationship between government deficits, money growth, and inflation', Journal of Macroeconomics, 7(4), 447-467.

Balke, N. S. \& Fomby, T. B. (1997), 'Threshold cointegration', International Economic Review, 38(3), 627-45.

Barro, R. J. (1979), 'On the determination of the public debt', Journal of Political Economy, 87(5), 940-71.

Chan, K. S. (1993), 'Consistency and limiting distribution of the least squares estimator of a threshold autoregressive model', The Annals of Statistics, 21, 520-533.

Darrat, A. F. (1988), 'Have large budget deficits caused rising trade deficits?', Southern Economic Journal 54(4), 879-887.

De Haan, J. \& Zelhorst, D. (1990), 'The impact of government deficits on money growth in developing countries', Journal of International Money and Finance 9(4), 455-469.

Dickey, D., F. W. (1979), 'Distribution of the estimators for autoregressive time series with a unit root', Journal of the American Statistical Association 74, 427-431.

Domaç, I. \& Yücel, E. M. (2005), 'What triggers inflation in emerging market economies?', Review of World Economics 141(1), 141-164.

Dwyer, Gerald P, J. (1982), 'Inflation and government deficits', Economic Inquiry 20(3), 315-29.

Elmendorf, D. \& Mankiw, N. (1999), Government debt, Handbook of Macroeconomics, Vol. C, pp.1615-1669. North-Holland, Amsterdam.

Enders, W. \& Siklos, P. L. (2001), 'Cointegration and threshold adjustment', Journal of Business \& Economic Statistics 19(2), 166-76.

Engle, R. F. \& Granger, C. W. J. (1987), 'Co-integration and error correction: Representation, estimation, and testing', Econometrica 55(2), 251-76.

Frankel, J. A. (1976) "A Monetary Approach to the Exchange Rate: Doctrinal Aspects and Empirical Evidence", Scandanevian Journal of Economics, 78, 169-191.

Frankel, J. A. (1979) 'On the Mark: A Theory of Floating Exchange Rate Based on Interest Rate Differentials', American Economic Review, 69, 610-622.

Friedman, M. (1968), 'The role of monetary policy', American Economic Review $58,1-17$. 
Giannaros, D. S. \& Kolluri, B. R. (1986), 'Deficit spending, money, and inflation: Some international empirical evidence', Journal of Macroeconomics 7(3), 401-417.

Hamburger, M. J. \& Zwick, B. (1981), 'Deficits, money and inflation', Journal of Monetary Economics 7(1), 141-150.

Hillbom, E., (2012) 'Botswana: A development-oriented gate-keeping state', African Affairs, 111 (442): 67-89

Kapetanios, G.,Y. Shin, A. Snell (2003) Testing for a unit root in the nonlinear framework, Journal of Econometrics, 112 (2), pp. 359-379.

Karras, G. (1994), 'Macroeconomic effects of budget deficits: further international evidence', Journal of International Money and Finance 13(2), 190-210.

King, R. G. \& Plosser, C. I. (1985), 'Money, deficits, and inflation', CarnegieRochester Conference Series on Public Policy 22(1), 147-195.

Lin, H.-Y. \& Chu, H.-P. (2013), 'Are fiscal deficits inflationary?', Journal of International Money and Finance 32, 214-233.

Loungani, P. \& Swagel, P. (2003), Sources of inflation in developing countries., Cambridge University Press, Cambridge, pp. 207-232.

Patinkin, D. (1965), Money, Interest, and Prices., Harper and Row, Publishers, New York.

Petrucelli, J. \& Woolford., S. (1984), 'A threshold ar(1) model', Journal of Applied Probability 21, 270-286.

Phillips, P., P. P. (1988), 'Testing for a unit root in time series regression', Biometrica $75,335-346$.

Protopapadakis, A. A. \& Siegel, J. J. (1987), 'Are money growth and inflation related to government deficits? evidence from ten industrialized economies', Journal of International Money and Finance 6(1), 31-48.

Sichel, D. (1993), 'Business cycle asymmetry: A deeper look', Economic Inquiry 31, 224-236.

Sollis, R. (2009) A simple unit root test against asymmetric STAR nonlinearity with an application to real exchange rates in Nordic countries,

Economic Modelling, Volume 26, Issue 1, Pages 118-125.

Sollis, R, Stephen J. Leybourne, Paul Newbold (2002) Tests for Symmetric and Asymmetric Nonlinear Mean Reversion in Real Exchange Rates, Journal of Money, Credit, and Banking, Volume 34, Number 3 (Part 1), pp. 686-700.

Taylor, M. P (1995). 'The Economics of Exchange Rates,' Journal of Economic Literature, 83:1, 13-47. 


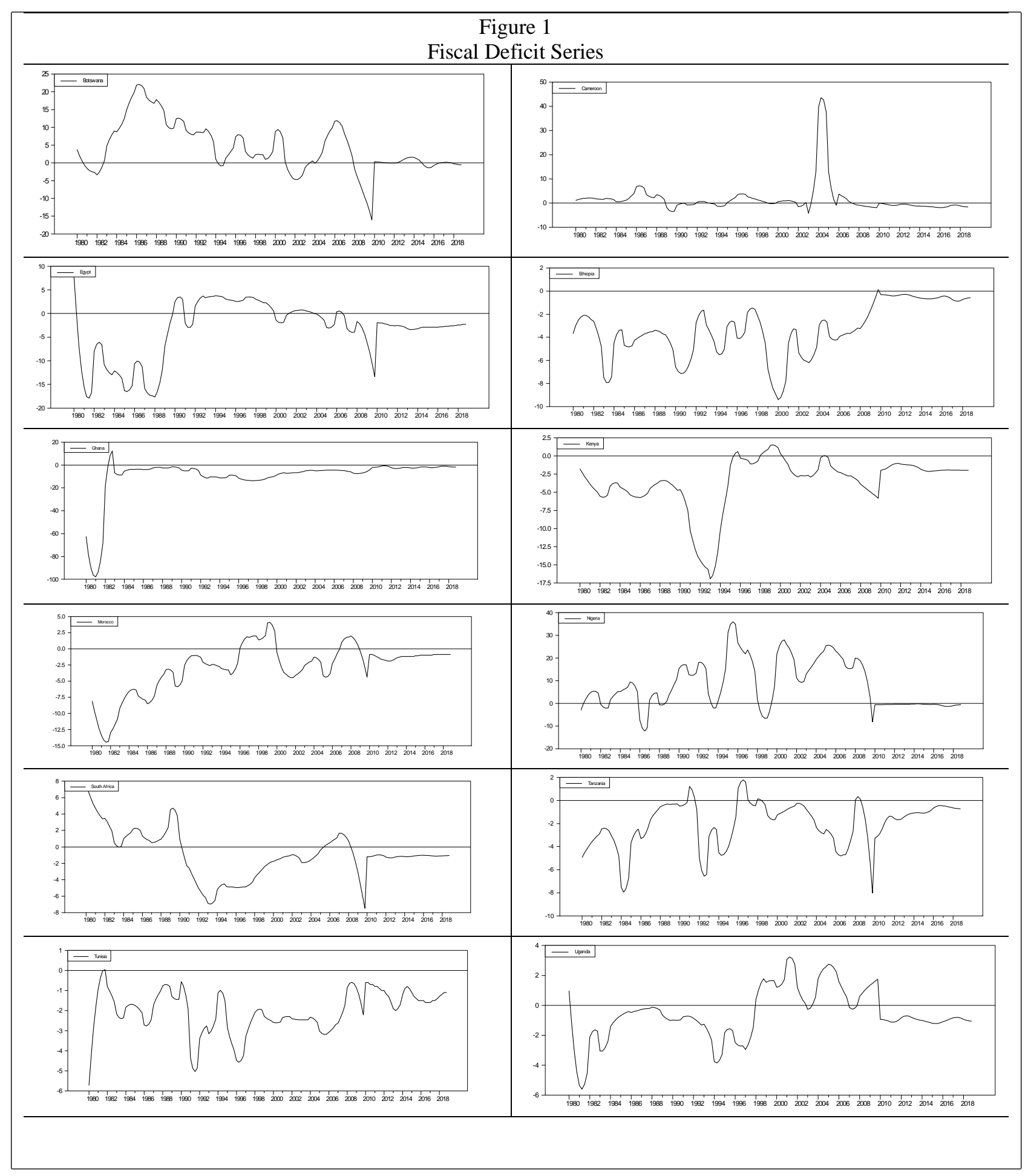




\section{Table 1: Unit Root Test}

\begin{tabular}{lllll|llll}
\hline Country & ADF & & & & PP & & & \\
\hline & FD & $\Delta$ FD & INFR & $\Delta$ INFR & FD & $\Delta$ FD & INFR & $\Delta$ INFR \\
\hline Botswana & -2.05 & $-9.25^{* *}$ & -1.92 & $-5.65^{* *}$ & -2.84 & $-9.37^{* *}$ & -2.38 & $-12.39^{* *}$ \\
Cameroon & -2.95 & $-4.13^{* *}$ & -2.89 & $-7.94^{* *}$ & -2.18 & $-10.38^{* *}$ & -2.10 & $-21.63^{* *}$ \\
Egypt & -2.89 & $-8.88^{* *}$ & -2.07 & $-10.22^{* *}$ & -2.95 & $-8.96^{* *}$ & -2.00 & $-12.87^{* *}$ \\
Ethiopia & -2.89 & $-4.85^{* *}$ & -2.37 & $-9.44^{* *}$ & -2.88 & $-6.24^{* *}$ & -2.25 & $-8.19^{* *}$ \\
Ghana & -0.84 & $-6.05^{* *}$ & -2.94 & $-6.43^{* *}$ & -2.80 & $-6.80^{* *}$ & -1.87 & $-7.91^{* *}$ \\
Kenya & -2.42 & $-4.30^{* *}$ & -2.29 & $-8.42^{* *}$ & -2.46 & $-5.88^{* *}$ & -2.68 & $-7.87^{* *}$ \\
Morocco & -2.97 & $-7.49^{* *}$ & -1.95 & $-11.76^{* *}$ & -2.11 & $-7.36^{* *}$ & -2.25 & $-21.20^{* *}$ \\
Nigeria & -2.58 & $-7.95^{* *}$ & -2.54 & $-5.64^{* *}$ & -2.92 & $-6.44^{* *}$ & -2.52 & $-6.61^{* *}$ \\
South Africa & -2.77 & $-9.68^{* *}$ & -2.83 & $-6.37^{* *}$ & -2.92 & $-9.64^{* *}$ & -2.95 & $-10.36^{* *}$ \\
Tanzania & -2.09 & $-8.90^{* *}$ & -2.42 & $-9.61^{* *}$ & -2.37 & $-9.41^{* *}$ & -2.55 & $-21.24^{* *}$ \\
Tunisia & -1.30 & $-8.73^{* *}$ & -1.73 & $-11.29^{* *}$ & -2.61 & $-8.13^{* *}$ & -2.70 & $-8.69^{* *}$ \\
Uganda & -2.20 & $-8.77^{* *}$ & -2.61 & $-3.83^{* *}$ & -2.60 & $-7.54^{* *}$ & -2.19 & $-13.92^{* *}$ \\
\hline Note: & & &
\end{tabular}

Note: $^{*}$ and ${ }^{* *}$ denote significant at 5 and 1 per cent levels respectively 
Table 2: Johansen Cointegration Tests

\begin{tabular}{|c|c|c|c|c|c|c|}
\hline Country & $\mathrm{H}_{0}$ & $\mathrm{H}_{1}$ & Test Stat & CV & Results & Cointegrating Vector \\
\hline Botswana & $\begin{array}{l}J_{\text {trace }} \\
r=0 \\
r=1 \\
J_{\text {max }} \\
r=0 \\
r=1\end{array}$ & $\begin{array}{l}r>0 \\
r>1 \\
r=1 \\
r=2\end{array}$ & $\begin{array}{c}37.34 \\
10.5 \\
\\
26.83 \\
10.5 \\
\end{array}$ & $\begin{array}{c}18.34 \\
3.84 \\
\\
17.15 \\
3.84 \\
\end{array}$ & $\begin{array}{l}\text { Reject } \mathrm{H}_{0} \\
\text { Reject } \mathrm{H}_{0} \\
\text { Reject } \mathrm{H}_{0} \\
\text { Reject } \mathrm{H}_{0}\end{array}$ & $(1-0.29)$ \\
\hline Cameroon & $\begin{array}{l}J_{\text {trace }} \\
r=0 \\
r=1 \\
J_{\max } \\
r=0 \\
r=1\end{array}$ & $\begin{array}{l}r>0 \\
r>1 \\
r=1 \\
r=2\end{array}$ & $\begin{array}{l}64.29 \\
30.85 \\
\\
33.45 \\
30.85 \\
\end{array}$ & \begin{tabular}{r|}
18.4 \\
3.84 \\
\\
17.15 \\
3.84 \\
\end{tabular} & $\begin{array}{l}\text { Reject } \mathrm{H}_{0} \\
\text { Reject } \mathrm{H}_{0} \\
\text { Reject } \mathrm{H}_{0} \\
\text { Reject } \mathrm{H}_{0}\end{array}$ & $(1,-0.25)$ \\
\hline Egypt & $\begin{array}{l}J_{\text {trace }} \\
r=0 \\
r=1 \\
J_{\max } \\
r=0 \\
r=1\end{array}$ & $\begin{array}{l}r>0 \\
r>1 \\
r=1 \\
r=2\end{array}$ & $\begin{array}{c}36.92 \\
6.51 \\
\\
30.41 \\
6.51 \\
\end{array}$ & \begin{tabular}{r|}
18.4 \\
3.84 \\
\\
17.14 \\
3.84 \\
\end{tabular} & $\begin{array}{l}\text { Reject } \mathrm{H}_{0} \\
\text { Reject } \mathrm{H}_{0} \\
\text { Reject } \mathrm{H}_{0} \\
\text { Reject } \mathrm{H}_{0}\end{array}$ & $(1,0.92)$ \\
\hline Ethiopia & $\begin{array}{l}J_{\text {trace }} \\
r=0 \\
r=1 \\
J_{\max } \\
r=0 \\
r=1\end{array}$ & $\begin{array}{l}r>0 \\
r>1 \\
r=1 \\
r=2\end{array}$ & $\begin{array}{l}59.73 \\
19.58 \\
\\
40.14 \\
19.58 \\
\end{array}$ & $\begin{array}{c}18.4 \\
3.84 \\
\\
17.14 \\
3.84 \\
\end{array}$ & $\begin{array}{l}\text { Reject } \mathrm{H}_{0} \\
\text { Reject } \mathrm{H}_{0} \\
\text { Reject } \mathrm{H}_{0} \\
\text { Reject } \mathrm{H}_{0}\end{array}$ & $(1,3.03)$ \\
\hline Ghana & $\begin{array}{l}J_{\text {trace }} \\
r=0 \\
r=1 \\
J_{\max } \\
r=0 \\
r=1\end{array}$ & $\begin{array}{l}r>0 \\
r>1 \\
r=1 \\
r=2\end{array}$ & $\begin{array}{l}94.21 \\
42.96 \\
\\
51.26 \\
42.96 \\
\end{array}$ & $\begin{array}{c}18.4 \\
3.84 \\
\\
17.14 \\
3.84 \\
\end{array}$ & $\begin{array}{l}\text { Reject } \mathrm{H}_{0} \\
\text { Reject } \mathrm{H}_{0} \\
\text { Reject } \mathrm{H}_{0} \\
\text { Reject } \mathrm{H}_{0}\end{array}$ & $(1,0.16)$ \\
\hline Kenya & $\begin{array}{l}J_{\text {trace }} \\
r=0 \\
r=1 \\
J_{\max } \\
r=0 \\
r=1\end{array}$ & $\begin{array}{l}r>0 \\
r>1\end{array}$ & $\begin{array}{l}32.03 \\
11.28\end{array}$ & $\begin{array}{l}18.4 \\
3.84\end{array}$ & $\begin{array}{l}\text { Reject } \mathrm{H}_{0} \\
\text { Reject } \mathrm{H}_{0}\end{array}$ & $(1,1.27)$ \\
\hline
\end{tabular}


Table 2 Cont'd: Johansen Cointegration Tests

\begin{tabular}{|c|c|c|c|c|c|c|}
\hline Country & $\mathrm{H}_{0}$ & $\mathrm{H}_{1}$ & Test Stat & $\mathrm{CV}$ & Results & Cointegrating Vector \\
\hline \multirow{6}{*}{ Morocco } & $\mathrm{J}_{\text {trace }}$ & & & & & \multirow{6}{*}{$(1,0.87)$} \\
\hline & $\mathrm{r}=0$ & $r>0$ & 18.78 & 18.4 & Reject $\mathrm{H}_{0}$ & \\
\hline & $\mathrm{r}=1$ & $r>1$ & 6.01 & 3.84 & Reject $\mathrm{H}_{0}$ & \\
\hline & $\mathrm{J}_{\max }$ & & & & & \\
\hline & $\mathrm{r}=0$ & $r=1$ & 12.77 & 17.14 & Reject $\mathrm{H}_{0}$ & \\
\hline & $\mathrm{r}=1$ & $\mathrm{r}=2$ & 6.01 & 3.84 & Reject $\mathrm{H}_{0}$ & \\
\hline \multirow{6}{*}{ Nigeria } & $\mathrm{J}_{\text {trace }}$ & & & & & \multirow{6}{*}{$(1,1.09)$} \\
\hline & $\mathrm{r}=0$ & $r>0$ & 20.11 & 18.4 & Reject $\mathrm{H}_{0}$ & \\
\hline & $r=1$ & $r>1$ & 8.96 & 3.84 & Reject $\mathrm{H}_{0}$ & \\
\hline & $\mathbf{J}_{\max }$ & & & & & \\
\hline & $r=0$ & $r=1$ & 11.15 & 17.14 & Reject $\mathrm{H}_{0}$ & \\
\hline & $\mathrm{r}=1$ & $\mathrm{r}=2$ & 8.96 & 3.84 & Reject $\mathrm{H}_{0}$ & \\
\hline \multirow{6}{*}{ South Africa } & $\mathrm{J}_{\text {trace }}$ & & & & & \multirow{6}{*}{$(1,1.46)$} \\
\hline & $\mathrm{r}=0$ & $r>0$ & 20.53 & 18.4 & Reject $\mathrm{H}_{0}$ & \\
\hline & $r=1$ & $r>1$ & 7.67 & 3.84 & Reject $\mathrm{H}_{0}$ & \\
\hline & $\mathbf{J}_{\max }$ & & & & & \\
\hline & $r=0$ & $\mathrm{r}=1$ & 12.87 & 17.14 & Reject $\mathrm{H}_{0}$ & \\
\hline & $\mathrm{r}=1$ & $\mathrm{r}=2$ & 7.67 & 3.84 & Reject $\mathrm{H}_{0}$ & \\
\hline \multirow{6}{*}{ Tanzania } & $\mathrm{J}_{\text {trace }}$ & & & & & \multirow{6}{*}{$(1,37.15)$} \\
\hline & $r=0$ & $r>0$ & 21.31 & 18.4 & Reject $\mathrm{H}_{0}$ & \\
\hline & $\mathrm{r}=1$ & $r>1$ & 7.16 & 3.84 & Reject $\mathrm{H}_{0}$ & \\
\hline & $\mathbf{J}_{\max }$ & & & & & \\
\hline & $r=0$ & $r=1$ & 14.15 & 17.14 & Reject $\mathrm{H}_{0}$ & \\
\hline & $\mathrm{r}=1$ & $r=2$ & 7.16 & 3.84 & Reject $\mathrm{H}_{0}$ & \\
\hline \multirow{6}{*}{ Tunisia } & $\mathrm{J}_{\text {trace }}$ & & & & & \multirow{6}{*}{$(1,0.42)$} \\
\hline & $\mathrm{r}=0$ & $r>0$ & 49.13 & 18.4 & Reject $\mathrm{H}_{0}$ & \\
\hline & $r=1$ & $r>1$ & 11.12 & 3.84 & Reject $\mathrm{H}_{0}$ & \\
\hline & $\mathbf{J}_{\max }$ & & & & & \\
\hline & $r=0$ & $r=1$ & 38.01 & 17.14 & Reject $\mathrm{H}_{0}$ & \\
\hline & $r=1$ & $r=2$ & 11.12 & 3.84 & Reject $\mathrm{H}_{0}$ & \\
\hline \multirow{6}{*}{ Uganda } & $\mathrm{J}_{\text {trace }}$ & & & & & \multirow{6}{*}{$(1,5.65)$} \\
\hline & $r=0$ & $r>0$ & 21.89 & 18.4 & Reject $\mathrm{H}_{0}$ & \\
\hline & $r=1$ & $r>1$ & 6.02 & 3.84 & Reject $\mathrm{H}_{0}$ & \\
\hline & $\mathbf{J}_{\max }$ & & & & & \\
\hline & $r=0$ & $r=1$ & 1587 & 17.14 & Reject $\mathrm{H}_{0}$ & \\
\hline & $\mathrm{r}=1$ & $r=2$ & 6.02 & 3.84 & Reject $\mathrm{H}_{0}$ & \\
\hline
\end{tabular}


Table 3: The Standard Cointegration Test

\begin{tabular}{lllr}
\hline \multicolumn{1}{c}{ Country } & \multicolumn{1}{c}{$\boldsymbol{p}$} & \multicolumn{1}{c}{ AIC } & Lags \\
\hline Botswana & $-0.104(-3.538)^{* *}$ & 833.66 & 2 \\
Cameroon & $-0.231(-5.296)^{* * *}$ & 1167.71 & 6 \\
Egypt & $-0.188(-4.663)^{* * *}$ & 1140.08 & 5 \\
Ethiopia & $-0.181(-3.791)^{* *}$ & 1279.68 & 2 \\
Ghana & $-0.127(-3.086)^{* *}$ & 1488.43 & 7 \\
Kenya & $-0.239(-4.131)^{* * *}$ & 1160.41 & 2 \\
Morocco & $-0.196(-4.274)^{* * *}$ & 881.55 & 5 \\
Nigeria & $-0.097(-3.437)^{* *}$ & 1306.74 & 2 \\
South Africa & $-0.067(-2.630)$ & 867.61 & 5 \\
Tanzania & $-0.011(-2.713)$ & 1306.42 & 3 \\
Tunisia & $-0.075(-3.142)^{*}$ & 604.00 & 5 \\
Uganda & $-0.071(-2.637)$ & 17.26 .94 & 2 \\
\hline
\end{tabular}

Note: The critical values of t-statistics for the null hypothesis $p=0$ with two variables in the cointegrationg relationship are $-4.00,-3.37$ and-3.02 and at 1,5 and 10 per cent levels of significance respectively. ${ }^{* * *},{ }^{* * *}$ indicate significance levels at 10,5 and 1 percent. 
Table 4: Threshold Cointegration Test with TAR Model

\begin{tabular}{|c|c|c|c|c|c|c|c|}
\hline Country & $\rho_{1}$ & $\rho_{2}$ & $\phi_{\mathrm{u}}$ & $\rho_{1}=\rho_{2}$ & AIC & Lags & $\tau$ \\
\hline \multicolumn{8}{|c|}{ Asymmetric adjustment with $\tau=0$} \\
\hline Botswana & -0.138 & -0.057 & $7.339^{* * *}$ & 1.985 & 828.29 & 2 & 0 \\
\hline Cameroon & -0.231 & -0.134 & $14.022^{* * *}$ & 0.001 & 1151.91 & 6 & 0 \\
\hline Egypt & -0.146 & -0.110 & 4.157 & 0.239 & 1066.63 & 5 & 0 \\
\hline Ethiopia & -0.242 & -0.247 & $18.917^{\text {*** }}$ & 0.003 & 1263.95 & 2 & 0 \\
\hline Ghana & -0.172 & -0.049 & $6.580^{*}$ & 2.322 & 1321.02 & 10 & 0 \\
\hline Kenya & -0.327 & -0.224 & $18.250^{* * *}$ & 1.445 & 1146.53 & 2 & 0 \\
\hline Morocco & -0.229 & -0.214 & $10.936^{* * *}$ & 0.029 & 871.39 & 2 & 0 \\
\hline Nigeria & -0.096 & -0.150 & $8.400^{* * * *}$ & 0.846 & 1287.90 & 2 & 0 \\
\hline South Africa & -0.069 & -0.067 & 3.462 & 0.002 & 858.43 & 2 & 0 \\
\hline Tanzania & -0.167 & -0.042 & 5.073 & $2.638^{*}$ & 1274.55 & 3 & 0 \\
\hline Tunisia & -0.044 & -0.039 & 1.690 & 0.008 & 552.46 & 5 & 0 \\
\hline Uganda & -0.077 & -0.012 & 2.548 & 0.682 & 1699.61 & 2 & 0 \\
\hline Country & $\rho_{1}$ & $\rho_{2}$ & $\phi_{\mathrm{u}}$ & $\rho_{1}=\rho_{2}$ & AIC & Lags & $\tau$ \\
\hline \multicolumn{8}{|c|}{ Asymmetric adjsutment with $\tau=$ threshold } \\
\hline Botswana & -0.205 & -0.046 & $10.234^{* * *}$ & $7.331^{* * *}$ & 823.00 & 2 & -1.297 \\
\hline Cameroon & -0.157 & -0.120 & $7.983^{* * *}$ & 2.232 & 1085.01 & 6 & -4.447 \\
\hline Egypt & -0.209 & -0.069 & $6.128^{* *}$ & $3.972^{* *}$ & 1062.77 & 5 & 10.145 \\
\hline Ethiopia & -0.218 & -0.376 & $20.818^{* * *}$ & $3.036^{*}$ & 1260.86 & 2 & -1.696 \\
\hline Ghana & -0.237 & 0.085 & $19.007^{* * *}$ & $25.332^{* * *}$ & 1298.25 & 10 & 8.023 \\
\hline Kenya & -0.335 & -0.194 & $18.935^{* * *}$ & 2.562 & 1145.40 & 2 & -4.253 \\
\hline Morocco & -0.479 & -0.282 & $14.652^{* * *}$ & $6.513^{* * *}$ & 864.88 & 2 & -3.922 \\
\hline Nigeria & -0.098 & -0.289 & $9.998^{* * *}$ & $3.735^{*}$ & 1284.97 & 2 & -1.826 \\
\hline South Africa & -0.129 & -0.051 & 4.323 & 1.647 & 856.75 & 2 & 7.704 \\
\hline Tanzania & -0.411 & -0.050 & 3.439 & $14.760^{* * *}$ & 1262.71 & 3 & 1.761 \\
\hline Tunisia & -0.016 & -0.114 & $9.938^{* * * *}$ & $4.400^{* * *}$ & 547.93 & 5 & -2.271 \\
\hline Uganda & -0.179 & 0.036 & 4.364 & $13.923^{* * *}$ & 1686.64 & 2 & 1.391 \\
\hline
\end{tabular}

Note: The selected lag length ensures that the residuals from the estimated regressions are serially uncorrelated. ${ }^{*},{ }^{* *},{ }^{* * *}$ indicates significance at 10,5 and 1 per cent levels respectively. 
Table 5: Threshold Cointegration Test with MTAR Model

\begin{tabular}{|c|c|c|c|c|c|c|c|}
\hline Country & $\rho_{1}$ & $\rho_{2}$ & $\phi_{\mathrm{u}}$ & $\rho_{1}=\rho_{2}$ & AIC & Lags & $\tau$ \\
\hline & & \multicolumn{6}{|c|}{ Asymmetric adjustment with $\tau=0$} \\
\hline Botswana & -0.096 & -0.109 & $6.291^{*}$ & 0.048 & 830.26 & 2 & 0 \\
\hline Cameroon & -0.175 & -0.195 & $6.789^{*}$ & 0.050 & 1087.31 & 6 & 0 \\
\hline Egypt & -0.138 & -0.120 & 4.063 & 0.061 & 1066.81 & 5 & 0 \\
\hline Ethiopia & -0.173 & -0.311 & $21.387^{* * * *}$ & $3.944^{*}$ & 1259.95 & 2 & 0 \\
\hline Ghana & -0.229 & -0.035 & $7.758^{* * * *}$ & $4.503^{*}$ & 1318.71 & 10 & 0 \\
\hline Kenya & -0.275 & -0.307 & $17.439^{* * *}$ & 0.130 & 1147.87 & 2 & 0 \\
\hline Morocco & -0.255 & -0.186 & $11.275^{* * * *}$ & 0.622 & 870.79 & 2 & 0 \\
\hline Nigeria & -0.114 & -0.102 & $7.956^{* * *}$ & 0.042 & 1288.72 & 2 & 0 \\
\hline South Africa & -0.079 & -0.048 & 3.657 & 0.372 & 858.05 & 2 & 0 \\
\hline Tanzania & -0.142 & -0.070 & 4.104 & 0.792 & 1276.44 & 3 & 0 \\
\hline Tunisia & -0.061 & -0.025 & 2.029 & 0.670 & 551.77 & 5 & 0 \\
\hline Uganda & -0.089 & -0.040 & 2.447 & 0.486 & 1699.81 & 2 & 0 \\
\hline Country & $\rho_{1}$ & $\rho_{2}$ & $\phi_{\mathrm{u}}$ & $\rho_{1}=\rho_{2}$ & AIC & Lags & $\tau$ \\
\hline \multicolumn{8}{|c|}{ Asymmetric adjustment with $\tau=$ threshold } \\
\hline Botswana & -0.108 & -0.134 & $11.377^{* * * *}$ & $16.232^{* * *}$ & 837.88 & 2 & 0.935 \\
\hline Cameroon & -0.133 & -0.141 & $7.442^{* * *}$ & 1.207 & 1086.09 & 6 & 1.482 \\
\hline Egypt & -0.093 & -0.469 & $8.458^{* * *}$ & $8.383^{* * *}$ & 1058.33 & 5 & -3.797 \\
\hline Ethiopia & -0.185 & -0.423 & $24.720^{* * *}$ & $9.260^{* * *}$ & 1254.72 & 2 & -6.596 \\
\hline Ghana & -0.289 & -0.028 & $9.593^{* * *}$ & $7.901^{* * * *}$ & 1315.17 & 10 & 2.929 \\
\hline Kenya & -0.371 & -0.089 & $29.930^{* * *}$ & $20.390^{* * *}$ & 1128.39 & 2 & 6.177 \\
\hline Morocco & -0.196 & -0.544 & $13.534^{* * * *}$ & $4.562^{*}$ & 866.81 & 2 & -2.024 \\
\hline Nigeria & -0.023 & -0.128 & $9.069^{* * *}$ & 2.054 & 1286.67 & 2 & 7.484 \\
\hline South Africa & -0.394 & -0.054 & $8.261^{* * * *}$ & $9.173^{* * * *}$ & 849.289 & 2 & 2.229 \\
\hline Tanzania & -0.426 & -0.018 & $14.399^{* * * *}$ & $20.399^{* * *}$ & 1257.5 & 3 & 3.186 \\
\hline Tunisia & -0.214 & -0.024 & $9.074^{* * *}$ & $6.619^{* * *}$ & 545.68 & 5 & 0.924 \\
\hline Uganda & -0.268 & -0.004 & $8.337^{\text {**** }}$ & $11.927^{* * *}$ & 1688.53 & 2 & -2.241 \\
\hline
\end{tabular}

Note: The selected lag length ensures that the residuals from the estimated regressions are serially uncorrelated. ${ }^{*},{ }^{* *},{ }^{* * *}$ indicates significance at 10, 5 and 1 per cent levels respectively. 
Table 6: Asymmetric Error-Correction Models

\begin{tabular}{|c|c|c|c|c|c|c|}
\hline \multirow[b]{2}{*}{ Country } & \multirow{2}{*}{$\begin{array}{c}\text { Linear ECM } \\
\rho \rho\end{array}$} & \multicolumn{3}{|c|}{ Threshold ECM } & \multirow[b]{2}{*}{ Flag } & \multirow[b]{2}{*}{$\tau$} \\
\hline & & Lags & $\rho_{11}$ & $\rho_{12}$ & & \\
\hline Botswana & & & & & TAR & \\
\hline$\triangle \mathrm{INFR}$ & $-0.311(-3.845)^{* * * *}$ & 3 & $-0.124(-0.164)$ & $-0.206(-4.541)^{* * * *}$ & & 1.297 \\
\hline$\Delta \mathrm{FD}$ & $-0.211(-2.472)^{* *}$ & & $-0.147(3.866)^{* * *}$ & $0.098(1.298)$ & & -0.964 \\
\hline Egypt & & & & & M-TAR & \\
\hline$\triangle \mathrm{INFR}$ & $-0.269(-4.291)^{* * *}$ & 4 & $-0.193(-2.081)^{*}$ & $-0.437(-4.841)^{* * *}$ & & -3.797 \\
\hline$\Delta \mathrm{FD}$ & $-0.185(-3.536)^{* * *}$ & & $-0.138(-2.682)^{* *}$ & $-0.087(-1.379)$ & & 1.435 \\
\hline Ethiopia & & & & & M-TAR & \\
\hline$\triangle \mathrm{INFR}$ & $-0.212(-5.833)^{* * *}$ & 3 & $-0.318(-0.865)$ & $-0.567(-3.843)^{* * *}$ & & -6.506 \\
\hline$\Delta \mathrm{FD}$ & $-0.178(-4.155)^{* * *}$ & & $-0.446(-4.691)^{* * *}$ & $-0.208(-1.465)$ & & 2.229 \\
\hline Ghana & & & & & TAR & \\
\hline$\triangle \mathrm{INFR}$ & $-0.274(-5.508)^{* * *}$ & 6 & $-0.532(-3.032)^{* * *}$ & $-0.322(-2.859)^{* *}$ & & 8.023 \\
\hline$\Delta \mathrm{FD}$ & $-0.196(-5.897)^{* * *}$ & & $-0.618(-4.001)^{* * *}$ & $-0.228(1.284)$ & & -4.911 \\
\hline Kenya & & & & & M-TAR & \\
\hline$\triangle \mathrm{INFR}$ & $-0.273(-6.151)^{* * *}$ & 4 & $-0.568(-4.955)^{* * *}$ & $-0.189(-0.908)$ & & 6.177 \\
\hline$\Delta \mathrm{FD}$ & $-0.132(-2.716)^{* *}$ & & $-0.256(-1.906)^{*}$ & $-0.106(-1.366)$ & & 0.903 \\
\hline Morocco & & & & & TAR & \\
\hline$\Delta \mathrm{INFR}$ & $-0.278(-4.143)^{* * * *}$ & 4 & $-0.345(-2.631)^{* *}$ & $-0.114(1.509)$ & & -3.922 \\
\hline$\Delta \mathrm{FD}$ & $-0.160(-3.133)^{* * *}$ & & $-0.497(-1.608)$ & $-0.154(0.884)$ & & -1.668 \\
\hline Nigeria & & & & & TAR & \\
\hline$\triangle \mathrm{INFR}$ & $-0.201(-4.150)^{* * *}$ & 3 & $-0.485(-4.117)^{* * *}$ & $-0.289(-3.285)^{* * *}$ & & -1.826 \\
\hline$\Delta \mathrm{FD}$ & $-0.192(-3.849)^{* * *}$ & & $-0.513(-3.510)^{* * *}$ & $-0.167(-0.891)$ & & 0.708 \\
\hline South Africa & & & & & M-TAR & \\
\hline$\Delta \mathrm{INFR}$ & $-0.171(-3.443)^{* * *}$ & 5 & $-0.228(-5.194)^{* * * *}$ & $-0.204(-1.005)$ & & 2.229 \\
\hline$\Delta \mathrm{FD}$ & $-0.142(-3.798)^{* * *}$ & & $-0.178(-2.085)^{*}$ & $-0.309(-4.111)^{* * *}$ & & -1.541 \\
\hline Tanzania & & & & & M-TAR & \\
\hline$\triangle \mathrm{INFR}$ & $-0.118(-4.279)^{* * *}$ & 4 & $-0.585(-4.896)^{* * *}$ & $-0.228(-1.065)$ & & 3.186 \\
\hline$\Delta \mathrm{FD}$ & $-0.175(-4.744)^{* * *}$ & & $-0.443(-5.001)^{* * *}$ & $-0.106(-1.489)$ & & -2.225 \\
\hline Tunisia & & & & & M-TAR & \\
\hline$\triangle \mathrm{INFR}$ & $-0.177(-3.418)^{* * *}$ & 4 & $-0.338(-3.862)^{* * *}$ & $-0.165(-2.867)^{* *}$ & & 0.924 \\
\hline$\Delta \mathrm{FD}$ & $-0.227(-4.487)^{* * *}$ & & $-0.486(-4.217)^{* * *}$ & $-0.228(-1.082)$ & & 1.439 \\
\hline Uganda & & & & & TAR & \\
\hline$\triangle \mathrm{INFR}$ & $-0.166(-2.358)^{* *}$ & 5 & $-0.409(-2.881)^{* *}$ & $0.226(1.206)$ & & 1.391 \\
\hline$\Delta \mathrm{FD}$ & $-0.178(-3.546)^{* * *}$ & & $-0.488(-4.599)^{* * *}$ & $-0.167(-1.980)^{* *}$ & & -2.181 \\
\hline
\end{tabular}

Note: ${ }^{*}, * *, * * *$ indicates significance at 10,5 and 1 per cent levels respectively with $\mathrm{t}$-statistic in parentheses. 